\title{
Glomerular epithelial foot processes and filtration slits in IDDM patients
}

\author{
S.F. Bjørn ${ }^{1}$, H-J. Bangstad ${ }^{2}$, K. F. Hanssen ${ }^{2}$, G. Nyberg ${ }^{3}$, J.D. Walker ${ }^{4}$, G. C. Viberti ${ }^{4}$, R. Østerby ${ }^{1}$ \\ ${ }^{1}$ Electron Microscopy Laboratory, Institute for Experimental Clinical Research, Medical Department M \\ (Diabetes and Endocrinology) and University Institute of Pathology, Aarhus Kommunehospital, Denmark \\ ${ }^{2}$ Aker Diabetes Research Center, Aker University Hospital, Oslo, Norway \\ ${ }^{3}$ Transplant Unit, Sahlgrenska Hospital, Göteborg, Sweden \\ ${ }^{4}$ Unit for Metabolic Medicine, UMDS, Guy's Hospital, London, UK
}

Summary Diabetic nephropathy is associated with functional changes in the glomerular filtration barrier but the structural counterpart remains unknown. Width of glomerular epithelial cell foot processes and of filtration slits were determined by morphometric methods in 11 non-diabetic kidney donors and in 28 diabetic patients with albumin excretion rates ranging from normal to proteinuria. Foot process width was estimated from the ratio of tuft surface density to length density of slits. At high magnification independently sampled, perpendicularly cut slits were classified. Foot process width on peripheral basement membrane was increased in microalbuminuric compared to normoalbuminuric diabetic patients $(p<0.05)$ but showed no significant correlation with the level of albumin excretion when patients with increased barrier permeability were considered. Width of filtration slits in normo- and micro- albuminuric diabetic patients exceeded that in nondiabetic control subjects $(p<0.05)$. Filtration slits were narrower in patients with overt proteinuria than in patients with microalbuminuria $(p<0.05)$ and correlated with glomerular filtration rate in all of the diabetic patients $(r=0.65, p<0.005)$. The results show that insulin-dependent diabetic patients with nephropathy present changes of epithelial cells and filtration slits, demonstrable already in the stage of microalbuminuria. The mechanism of albumin leakage is not achieved by these measures. The dimension of filtration slits may play a contributing role in the level of glomerular filtration rate in diabetic patients. [Diabetologia (1995) 38: 1197-1204]

Key words Albuminuria, diabetic glomerulopathy, diabetic nephropathy, filtration slits, glomerular epithelial cells, stereology.
Received: 4 January 1995 and in revised form: 20 March 1995

Corresponding author: Dr. S.F. Bjørn, Electron Microscopy Laboratory, Aarhus Kommunehospital, DK-8000 Aarhus C, Denmark

Abbreviations: IDDM, Insulin-dependent diabetes mellitus; GFR, glomerular filtration rate; AER, albumin excretion rate; $\mathrm{HbA}_{1 \mathrm{c}}$, glycated haemoglobin; ND, non-diabetic control subjects; $D_{\mathrm{NA}}$, diabetic patients with normal albumin excretion rate; $\mathrm{D}_{\mathrm{M}}$, diabetic patients with microalbuminuria; $\mathrm{D}_{\mathrm{P}}$, diabetic patients with proteinuria.; $\mathrm{CV}$, coefficient of variation ( $\mathrm{SD} /$ mean); $\mathrm{FPW}_{\mathrm{PBM}}$, width of foot processes on peripheral

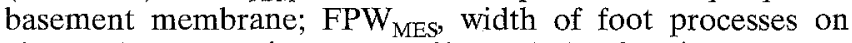
glomerular mesangium; ANOVA, analysis of variance; PBM, peripheral basement membrane.
Microalbuminuria in patients with insulin-dependent diabetes mellitus (IDDM) has been shown to predict overt diabetic nephropathy [1-3]. The clinical manifestations of overt nephropathy, characterized by proteinuria and declining glomerular filtration rate (GFR) are closely linked to structural changes in renal glomeruli [4-6]. A relationship between functional and structural changes has also been found at the stage of microalbuminuria [7-9]. However, the mechanisms and the structural counterpart of the increased permeability to albumin across the glomerular filter have not been identified.

The epithelial cells of renal glomeruli show widening of foot processes in proteinuric states such as minimal change nephrotic syndrome and glomerulonephritis $[10,11]$. In clinically proteinuric diabetic nephropathy widening of foot processes has also been doc- 
Table 1. Clinical data in diabetic patients and non-diabetic control subjects

\begin{tabular}{lrllllll}
\hline Group & $n$ & $\begin{array}{l}\text { Age } \\
\text { (years) }\end{array}$ & $\begin{array}{l}\text { Duration } \\
\text { of diabetes } \\
\text { (years) }\end{array}$ & $\begin{array}{l}\text { AER } \\
(\mu \mathrm{g} / \mathrm{min})\end{array}$ & $\begin{array}{l}\text { GFR } \\
\left(\mathrm{ml} \cdot \mathrm{min}^{-1} \cdot 1.73 \mathrm{~m}^{-2}\right)\end{array}$ & $\begin{array}{l}\text { Systolic blood } \\
\text { pressure } \\
(\mathrm{mm} \mathrm{Hg})\end{array}$ & $\begin{array}{l}\text { Diastolic blood } \\
\text { pressure } \\
(\mathrm{mmH})\end{array}$ \\
\hline $\mathrm{ND}$ & 11 & $45(21-58)$ & & & $104(86-121)$ & $120(110-145)$ & $80(70-90)$ \\
$\mathrm{D}_{\mathrm{NA}}$ & 9 & $33(19-39)$ & $11(5-31)$ & $5(2-7)$ & $129(96-176)$ & $122(106-142)$ & $73(51-102)$ \\
$\mathrm{D}_{\mathrm{MI}}$ & 9 & $21(17-52)$ & $13(8-22)$ & $65(23-180)$ & $132(117-193)$ & $130(90-138)$ & $85(52-90)$ \\
$\mathrm{D}_{\mathrm{P}}$ & 9 & $35(22-47)$ & $24(9-35)$ & $521(208-1609)$ & $36(21-145)$ & $170(118-200)$ & $96(78-120)$ \\
\hline
\end{tabular}

Data are median (and range). ND, Non-diabetic kidney donors; $\mathrm{D}_{\mathrm{NA}}$, diabetic patients with normoalbuminuria $(<20 \mu \mathrm{g} / \mathrm{min}) ; \mathrm{D}_{\mathrm{MI}}$, diabetic patients with microalbuminuria (AER $20-200 \mu \mathrm{g} / \mathrm{min}$ ); $\mathrm{D}_{\mathrm{P}}$, diabetic patients with proteinuria $(\mathrm{AER}>200 \mu \mathrm{g} / \mathrm{min})$

umented, but the association with the level of albumin excretion rate (AER) is controversial $[6,12]$ and knowledge of epithelial structural changes at the stage of microalbuminuria is scarse. In a previous study foot process width was reported to be similar in patients with microalbuminuria and patients with normal AER [12], while another found widening in a small group of patients with moderately elevated AER [13].

The functional importance of the filtration slit between the foot processes is not entirely clear. The relative roles of the basement membrane and the slit in restricting the escape of macromolecules have been a matter of dispute [14]. The filtration slit most likely constitutes the main path for the filtrate at the level of the epithelial cells, and new data indicate that the slit may play an important role in terms of water permeability $[15,16]$. These characteristics of the filtration barrier are of central interest in the diabetic kidney.

The present study is a morphometric investigation of the foot processes and the filtration slits in the renal glomeruli of IDDM patients with a range of AER from normal to heavy proteinuria and in normal control subjects. It was carried out with the main aim of studying the relationship between albumin excretion and the structural data. Furthermore, it was considered relevant to examine the relationship between the structural parameters and the level of GFR.

\section{Subjects, materials and methods}

Subjects. The diabetic patients were classified into three groups according to their urinary AER: below or equal to $20 \mu \mathrm{g} / \mathrm{min}$ was termed normoalbuminuria, $21-200 \mu \mathrm{g} / \mathrm{min}$ microalbuminuria, and above $200 \mu \mathrm{g} / \mathrm{min}$ proteinuria [17].

All patients in the present report have been included in earlier studies of diabetic glomerulopathy $[5,7-9]$. Renal biopsy was performed in patients older than 18 years after their written consent was given and the protocol was approved by the regional ethics committee. The patients in the normo- and microalbuminuric groups participated in a study of the natural history of diabetic nephropathy in IDDM [7] or in a clinical intervention trial of intensified insulin treatment of young microalbuminuric patients [9]. In the microalbuminuric group one patient was an outlier with respect to GFR and was excluded from this study. AER was measured in three timed overnight sterile urine samples collected during the year preceding the biopsy, and the patient classified into one of the three categories if at least two AER values met the category allocation criteria. GFR was calculated from the clearance of ${ }^{51} \mathrm{Cr}$ EDTA after a single intravenous injection or by inulin clearance during steady-state water diuresis, and values were corrected for a body surface area of $1.73 \mathrm{~m}^{2}$. Blood pressure was measured with patients sitting after $10 \mathrm{~min}$ rest and represents the mean of several measurements. Glycated haemoglobin $\mathrm{HbA}_{1 \mathrm{c}}$ was assayed by agar gel electrophoresis (Corning method', CibaCorning, Halstead, Denmark) or by an HPLC-method using a "Diamant"-machine (Bio-Rad, Richmond, Calif., USA).

Eleven donors who had undergone an extensive investigation to ensure normal renal function prior to nephrectomy served as a non-diabetic control group.

Clinical details for the groups are given in Table 1 . The mean age in the control group was higher than in each of the other groups. Duration of diabetes was longer in the patients with proteinuria compared to the normo- and microalbuminuric groups. GFR was increased for the normo- and microalbuminuric groups compared to both the control and the proteinuric group and blood pressure was increased in the proteinuric group. Only proteinuric patients were treated with antihypertensive medication. All the patients in that group had proliferative retinopathy, whereas patients in the other diabetic groups at most had only background retinopathy.

Renal biopsies. The diabetic patients underwent a percutaneous renal biopsy taken using a Tru-cut or a Biopty 18-gauge needle under ultrasound guidance. Each biopsy was immersed into the fixative, $2 \%$ glutaraldehyde in modified Tyrode buffer [18] and mailed in the fixative to the Electron Microcopy Laboratory in Aarhus.

Biopsies from the control subjects were taken as a cortical wedge biopsy during renal transplantation. Nine biopsies were taken immediately after blood circulation was re-established in the recipient, and two were taken just before the kidney was removed from the donor. The biopsies were immersion-fixed in $2 \%$ glutaraldehyde in cacodylate buffer and mailed to the Electron Microscopy laboratory in Aarhus for further preparation.

Cutting the tissue into small blocks, dehydration and embedding into Vestopal were carried out after a fixation time of 3-10 days, including 1-2 days in the mail, and thereafter storage at $4{ }^{\circ} \mathrm{C}$. Ultrathin sections were stained with uranyl acetate and lead citrate for electron microscopy.

\section{Morphometry}

Sampling of glomerular profiles and micrographs. From each biopsy at least three glomerular profiles were studied. The protocol ensured sampling independent of glomerular size and structure $[7-9,19]$ except that totally occluded glomeruli were ex- 


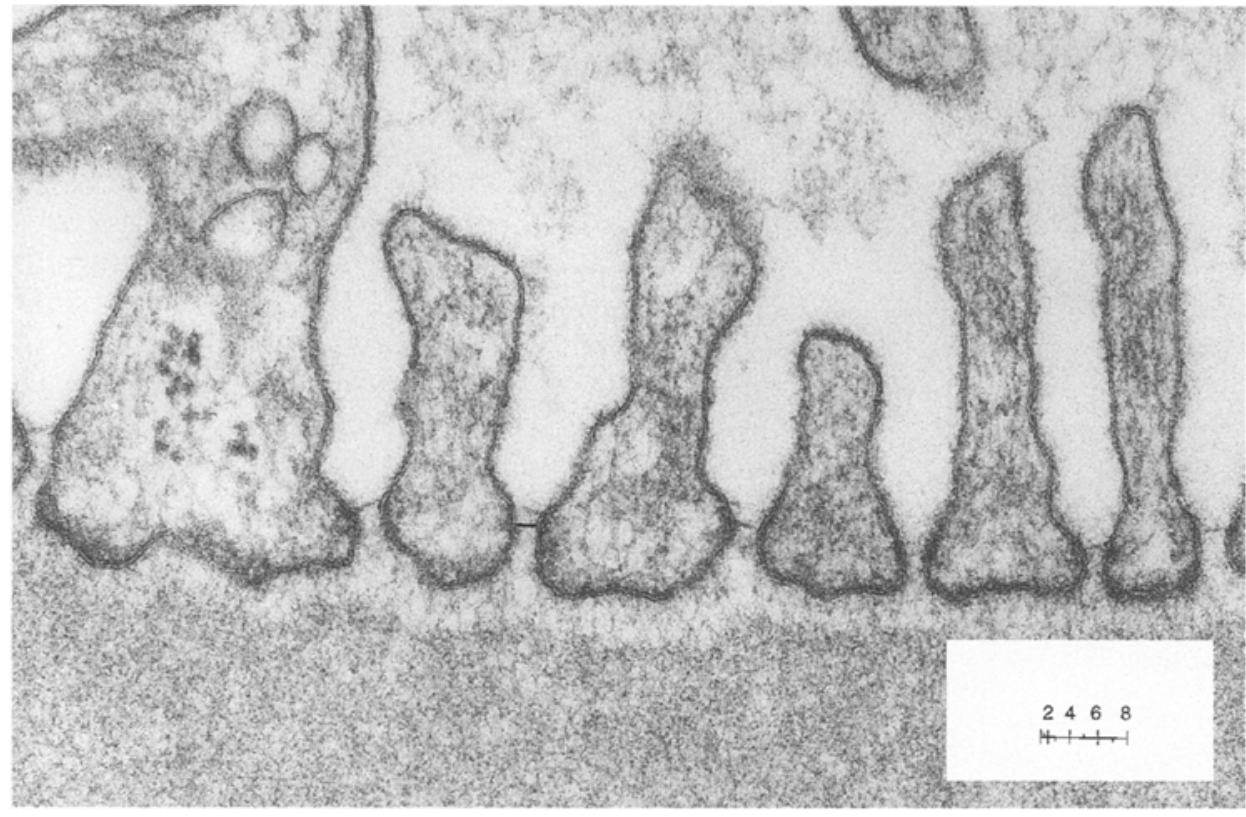

Fig.1. Foot processes with intervening slits on glomerular basement membrane. The bar illustrates a site acceptable for classification. The classification ruler is shown, with total length corresponding to $105 \mathrm{~nm}$. Magnification: $121,000 \times$

cluded. Width of foot processes was determined on micrographs at about $10,000 \times$ magnification, obtained by systematic random sampling with a predetermined sampling density. This was obtained by moving the specimen stage of the electron microscope (Philips CM 10 Eindhoven, Holland) at fixed steps. The sampling fraction was approximately $25 \%$, providing in the order of 45-50 micrographs per profile. The sampled level within each glomerulus was either a random level or the largest of a set of three levels, the set having a random position in the glomerulus.

Determination of slit width was done at a final magnification of $121,000 \times$, at a random level within glomeruli. Systematic random placing of fields was obtained as described above, but at each fixed step the observer was allowed to move the specimen from four predetermined points $(12,9,6,3$ "o'clock") to the centre of the visual field. The micrographs were taken in the position with the largest number of filtration slits present in the visual field thereby ensuring unbiased sampling with high efficiency.

Concurrently with the recordings for each glomerulus a carbon grating replica with 2160 lines per mm was photographed to determine the actual magnification.

Quantitation by electron microscopy. Average foot process width was estimated separately for mesangial and peripheral basement membrane surfaces as the ratio of the tuft surface and the length of filtration slits. The ratio equals the ratio of surface density/length density, using identical reference volume; i.e., the glomerular tuft. The estimate includes the width of one slit, which is negligible compared with the width of foot processes. The grid superimposed on the micrographs consisted of a counting frame within which the transsected slits were counted (Q), and test points and lines for counting points hitting the reference space, $\mathrm{P}($ tuft), and intersections with the surface trace $(I)$ [20]. Surface density $\left(S_{v}\right)$ equals:

$\mathrm{S}_{\mathrm{v}}(\mathrm{tuft} / \mathrm{ref})=2 * \Sigma \mathrm{I} /[(\mathrm{d} / \mathrm{mag}) * \Sigma \mathrm{P}(\mathrm{tuft})]\left(\mathrm{mm}^{-1}\right)$

where $\Sigma I$ is the total number of intersections between the surface trace and test lines, $d$ is the actual test line length per point in mm. Length density $\left(L_{v}\right)$ of the linear structure, the filtration slit, is estimated as
$\mathrm{L}_{\mathrm{v}}($ slits $/ \mathrm{ref})=2 * \Sigma \mathrm{Q} /[\mathrm{A} * \Sigma \mathrm{P}(\mathrm{tuft})]\left(\mathrm{mm}^{-2}\right)$

where $\Sigma \mathrm{Q}$ is the total number of transsected slits counted, $\mathrm{A}$ is the area corresponding to each point $\left(A=\mathrm{d}^{2} /\right.$ magnification $\left.^{2}\right)$.

Filtration slit width was classified on micrographs using a ruler with eight classes (Fig.1). The measurements were performed where the distance between two adjacent foot processes was smallest. This level was often in between the filtration slit diaphragm and the basement membrane. Since section thickness is in the same order or larger than the slit width "random orientation" cannot be used. When the angle between the plane of sectioning and the slit axis diverges from the perpendicular the delineation is blurred and the apparent width cannot be determined. Therefore, only slits cut perpendicular to their long axis were selected and "true width" was classified. Perpendicularity was determined by the appearance of neighbouring cell membranes as distinct, three-layered structures. On average $36 \%$ of all slits were classifiable (range $22-52 \%$, median $36.7 \%$ ) with no differences between the groups.

The total number of slits classified per biopsy varied between 71 and 231 (median 148). Slits on peripheral basement membrane and on mesangium were pooled because it was impossible to identify localization on most of the micrographs due to the high magnification.

These measurements were done by one observer (S. F.B.) who was blind to the patients' category.

\section{Statistical analysis}

Provided analysis of variance (ANOVA) indicated significant differences between groups, pairwise comparisons (corrected for multiple comparisons) were performed by Student-Newman-Keuls test and data are presented as mean and coefficient of variation (CV). Correlations were analysed using least-squares regression or Spearman rank order correlation (BMDP, SOLO statistical system, version 3.1). 


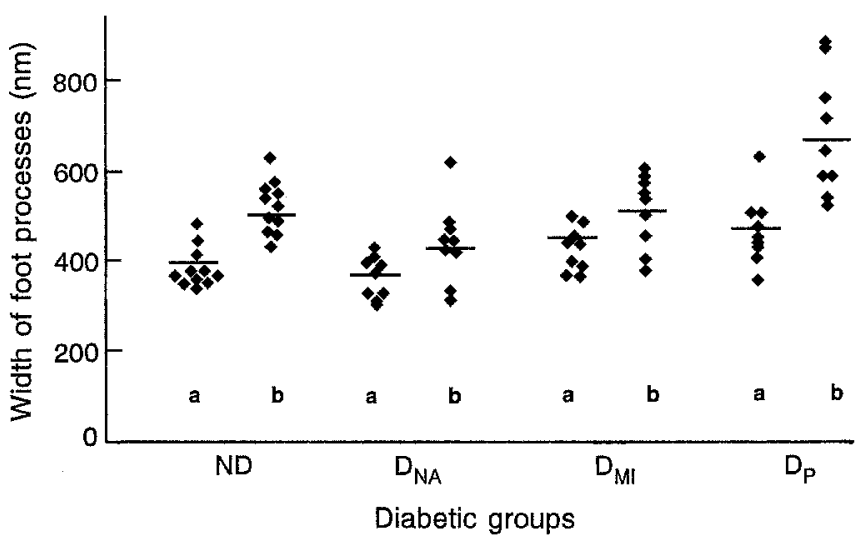

Fig. 2. $(a, b)$ Width of foot processes on peripheral basement membrane $(a)$ and on mesangial surface $(b)$. ND, Non-diabetic control group; diabetic groups: $\mathrm{D}_{\mathrm{NA}}$, normal albumin excretion; $\mathrm{D}_{\mathrm{MI}}$, microalbuminuria; $\mathrm{D}_{\mathrm{P}}$, proteinuria

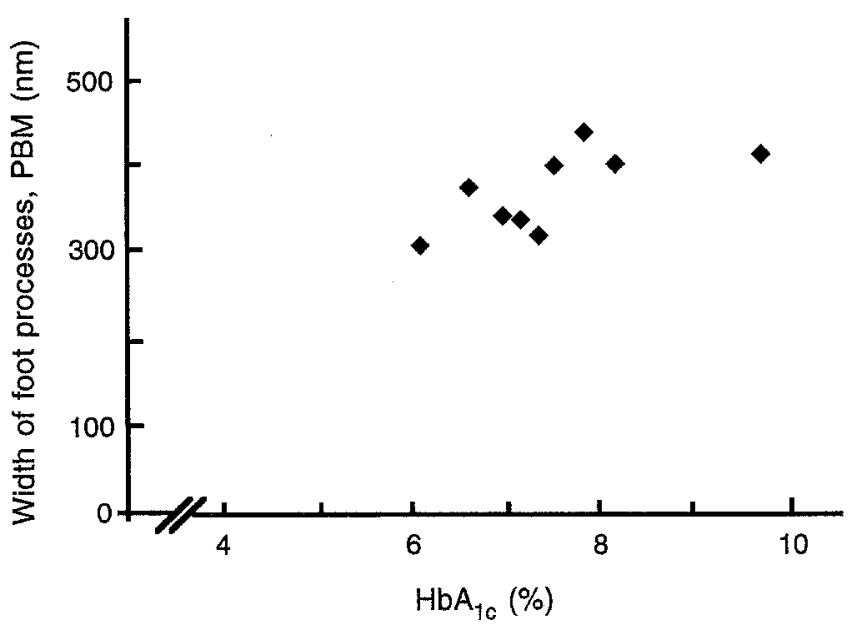

Fig. 3. Width of foot processes on peripheral basement membrane vs $\mathrm{HbA}_{1 \mathrm{c}}(r=0.67, p<0.05)$ in diabetic patients with normal AER

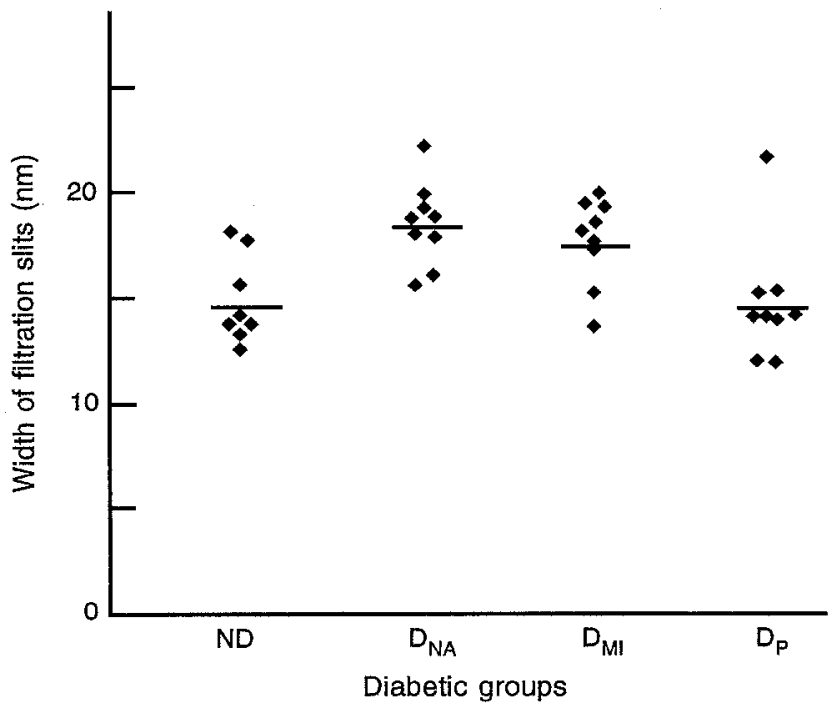

Fig. 4. Width of filtration slits on peripheral basement membrane and glomerular mesangium. The groups as in Fig. 2

\section{Results}

Width of foot processes on peripheral basement membrane and on mesangium is shown in Figure 2. Unweighted means ANOVA tested the groups to be different: width of foot process on peripheral basement membrane $\left(\mathrm{FPW}_{\mathrm{PBM}}\right) p=0.002$; glomerular mesangium $\left.\left(\mathrm{FPW}_{\mathrm{MES}}\right) p<0.001\right)$. Among the diabetic patients the overall tendency was widening of foot process width in patients with increased AER. On the peripheral basement membrane the increase was significant in microalbuminuric $\left(\mathrm{D}_{\mathrm{MI}}\right)$ patients compared with the patients with normal $\left(D_{\mathrm{NA}}\right)$ AER $\left(\mathrm{D}_{\mathrm{MI}} 442 \mathrm{~nm}(0.13)\right.$ vs $\left.\mathrm{D}_{\mathrm{NA}} 373 \mathrm{~nm}(0.12), p<0.05\right)$. No further significant increase was observed in the group with proteinuria compared to the microalbuminuria group. Comparing the proteinuria $\left(D_{p}\right)$ group with the control group the increase was significant $\left(\mathrm{D}_{\mathrm{P}} 478 \mathrm{~nm}(0.17)\right.$ vs control $\left.398(0.11), p<0,05\right)$. On glomerular mesangium the width of foot processes in the groups was as follows: control $500 \mathrm{~nm}$ (0.11), $\mathrm{D}_{\mathrm{NA}} 427 \mathrm{~nm}(0.22) ; \mathrm{D}_{\mathrm{P}} 672 \mathrm{~nm}(0.20), \mathrm{D}_{\mathrm{MI}}$ $503 \mathrm{~nm}(0.16)$, comparing proteinuric vs microalbuminuric- diabetic patients the increase was significant $(p<0.05)$. Because of the skewed distribution $\log \mathrm{FPW}_{\mathrm{MEs}}$ was calculated, and comparisons between groups were performed with geometric means. In both locations foot processes in the non-diabetic group tended to be wider than in the group of diabetic patients with normal AER.

A paired comparison in individual subjects of width of foot processes located on peripheral basement membrane and mesangium showed significantly wider foot processes on the mesangium in all of the groups (control $p<0.001, \mathrm{D}_{\mathrm{NA}} p<0.04, \mathrm{D}_{\mathrm{MI}}$ $\left.p<0.03, \mathrm{D}_{\mathrm{P}} p<0.003\right)$.

Width of mesangial foot processes correlated with $\log \operatorname{AER}(r=0.59, p=0.012)$ within the combined microalbuminuria and proteinuria group of diabetic patients. No correlations were found when correlating GFR with width of foot processes in any of the locations considering the diabetic patients all together. Within the diabetic normoalbuminuric group a positive correlation between width of foot processes and $\mathrm{HbA}_{1 \mathrm{c}}$ was observed both on the peripheral basement membrane ( $r=0.67, p<0.05$, Fig. 3) and on the mesangial surface $(r=0.84, p<0.005)$. All $\mathrm{HbA}_{1 \mathrm{c}}$ measurements were done in the same laboratory with the same technique.

Width of filtration slits is shown in Figure 4. Unweighted means ANOVA tested the groups to be different $(p<0.002)$. From the normo- to the microalbuminuric diabetic stage the mean filtration slit width was only slightly decreased but both mean widths were significantly higher than the width in the nondiabetic control subjects $\left(\mathrm{D}_{\mathrm{NA}} 18.4 \mathrm{~nm}(0.11)\right.$ vs control $14.7(0.14), p<0.05 ; \mathrm{D}_{\mathrm{MI}} 17.6 \mathrm{~nm}(0.12)$ vs control, $p<0.05)$. A significant decrease in width of fil- 


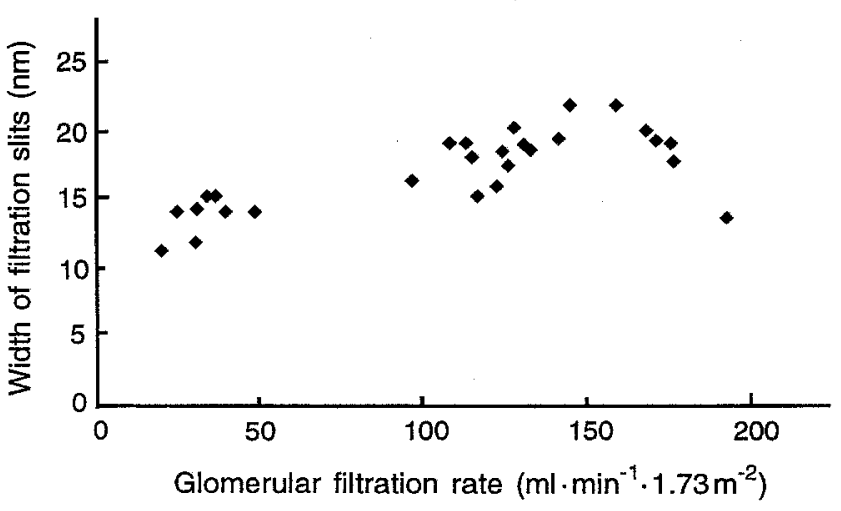

Fig.5. Width of filtration slits vs glomerular filtration rate $(r=0.65, p<0.005)$ in all of the diabetic patients

Table 2. Width of filtration slits; percentage distribution in classes

\begin{tabular}{lcccc}
\hline Class $^{\mathrm{a}}$ & $\mathrm{ND}(\mathrm{nm})$ & $\mathrm{D}_{\mathrm{NA}}(\mathrm{nm})$ & $\mathrm{D}_{\mathrm{MI}}(\mathrm{nm})$ & $\mathrm{D}_{\mathrm{P}}(\mathrm{nm})$ \\
\hline 0 & $7.6 \pm 3.6$ & $5.7 \pm 3.1$ & $6.3 \pm 2.0$ & $8.3 \pm 4.0$ \\
$1-2$ & $20.2 \pm 7.7^{\mathrm{b}}$ & $11.5 \pm 3.4$ & $14.0 \pm 4.8$ & $19.2 \pm 7.3^{\mathrm{c}}$ \\
$5-8$ & $2.6 \pm 2.6$ & $5.8 \pm 4.8$ & $5.1 \pm 2.9^{\mathrm{d}}$ & $2.4 \pm 2.2$ \\
\hline
\end{tabular}

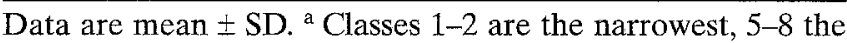
widest slits; ${ }^{b} \mathrm{ND}$ vs $\mathrm{D}_{\mathrm{NA}} p<0.02 ;{ }^{\mathrm{c}} \mathrm{D}_{\mathrm{P}}$ vs $\mathrm{D}_{\mathrm{NA}} p<0.02 ;{ }^{\mathrm{d}} \mathrm{D}_{\mathrm{MI}}$ vs $\mathrm{D}_{\mathrm{P}} p<0.04$. ND, Non-diabetic control group; $\mathrm{D}_{\mathrm{NA}}$, diabetic patients with normoalbuminuria; $\mathrm{D}_{\mathrm{MI}}$, with microalbuminuria; $\mathrm{D}_{\mathrm{P}}$, with proteinuria

tration slits was found in the diabetic group with proteinuria compared to both the micro- and the normoalbuminuric group $\left(\mathrm{D}_{\mathrm{P}} 14.6(0.20)\right.$ vs $\mathrm{D}_{\mathrm{NA}}, p<0.05$; $\mathrm{D}_{\mathrm{P}}$ vs $\left.\mathrm{D}_{\mathrm{MI}}, p<0.05\right)$. In the proteinuric group the slit width was similar to that in the control groups.

In all of the diabetic patients slit width correlated with GFR ( $r=0.65, p<0.005$, Fig.5). A weak tendency of inverse correlation with $\log A E R$ failed to reach statistical significance $(r=-0.43, p<0.08)$.

The percentage distribution in the lowest and the highest classes is shown in Table 2. Totally occluded slits were classified class 0 . They appeared as a fivelayered cell membrane and constituted about $7 \%$ of the total number of slits in all the groups.

No correlation between slit width and the adjacent foot process width was found $(r=0.15, p=0.17)$.

\section{Discussion}

This study demonstrates structural changes of the epithelial side of the glomerular filtration barrier in diabetic patients, demonstrable in patients with microalbuminuria, the earliest sign of diabetic nephropathy. The changes observed in these continuous variables are modest, and marked overlap among groups is clearly present. Still, the slight widening of foot processes on the peripheral basement membrane at the stage of microalbuminuria was present. This con- trasts with results in a previous publication [12] which may be due to the small group of microalbuminuric diabetic patients previously investigated.

In the correlations of structural observations to AER the two groups of diabetic patients with elevated AER were considered separately, since they represent different stages in the continuum of progressing diabetic nephropathy. In patients with normal AER it cannot be predicted who might develop nephropathy, and who will escape this complication [21]. There was no obvious relationship between increasingly elevated AER and further widening of foot processes of the peripheral basement membrane, although a positive correlation was found with foot processes on the mesangial surface. The observation of wider foot processes located on glomerular mesangium vs those on the peripheral basement membrane is in accord with findings in experimental studies with diabetic and normal rats $[22,23]$. The dissociation of observations concerning the mesangial and the peripheral surface might relate to different functions in the filtration process at the two locations. However, it should be mentioned that the estimate of mesangial foot process width tends to higher imprecision than that of the peripheral basement membrane, being based on fewer observations. The mesangial-urinary interface constitutes only approximately $25 \%$ of the total tuft surface.

The pathogenetic involvement of foot processes in the progression of diabetic nephropathy is not clear. As demonstrated in our data and reported for glomerulonephritis [11] widening of foot processes is not a necessary concomitant of increasing albuminuria. Changes in width might be a structural reaction to albumin escape through an abnormal basement membrane in an attempt to maintain the functional integrity of the barrier. The changes may also to some extent depend on the diabetic milieu especially in the early stage of disease as reflected in the positive correlation between foot process width and $\mathrm{HbA}_{1 \mathrm{c}}$ within the normoalbuminuric group. The results in this group are particularly interesting because there is no confounding influence of increased leakiness across the basement membrane. Within the other groups of patients it was not feasible to test the correlation because of the different methods of measurement.

The observation of wider foot processes in the non-diabetic control subjects compared with normoalbuminuric diabetic patients is unexplained. The differences in the methods of obtaining the renal tissue might play a role. The fact that kidney donors were older, and predominantly female does not seem to play a role, since neither the structural parameters utilised in this report, nor other glomerular structural parameters [24] showed any tendency to correlation with age or sex within the donor group.

The mean foot process width is a fairly crude parameter obtained by a simple measuring technique. 
Since the distribution of foot processes is markedly right-skewed [22], the arithmetical mean is not the optimal expression. Yet the intra-group variation was remarkably low, and the $\mathrm{CV}$ (SD/mean) was $0.11-0.17$. This measure has the advantage of being independent of the curvature of the filtration surface which influences the harmonic mean obtained from the distribution of apparent widths $[12,13,22]$ especially on the mesangial part of the surface. As expected, the arithmetic mean width of foot processes on peripheral basement membrane in human control biopsies estimated in this paper (400 $\mathrm{nm}$ ) exceeds the harmonic mean values found in previous studies, the range in previous publications being $225-304 \mathrm{~nm}$ $[12,13,22]$.

Quantitative data on the distribution of slit widths in human biopsies have not previously been published. The estimation requires sampling at a high magnification; a time-consuming process. The classification of true widths provides an UNBIased estimate of widths, since the probability of perpendicular sectioning is independent of the slit width. The absolute measures of the slit width vary with the tissue procurement [25]. In this investigation all of the biopsies were treated in the same way except that in the non-diabetic control group a different buffer was used and the biopsies were taken under anaesthesia after a period of ischaemia during the transplantation of the kidney. However, two donor biopsies were taken before removal of the kidney, i.e. avoiding the ischaemia period. The results in these two cases turned out to be in the upper and in the lower range of the group respectively.

The findings in this study reveal that a widening of slits is definitely not the long-sought explanation of increased albumin leakiness in early diabetic nephropathy. As discussed for the foot processes the structural changes may also be a consequence of changes in the proximal part of the barrier. It is noteworthy that diabetic patients with advanced nephropathy had slit widths similar to those of the control group. In the diabetic milieu a widening may take place, which is then modified in the later stages of nephropathy. The external cell layer has been proposed to contribute markedly to hydraulic permeability [15] and the changes observed may relate to the increased GFR in early stages of diabetes [26]. In the diabetic patients in this study a decrease in filtration slit width was observed in groups with an increase in AER and a decrease in GFR. This supports the notion that the filtration slit is likely to play a different role in the repulsion of the transglomerular flux of macromolecules and in that of water and solutes.

The slit membrane has been proposed as an important determinant of glomerular capillary hydraulic permeability, representing nearly half the resistance to water movement across the filtration barrier $[16$,
27]. These calculations are based on electron microscopy dimensional data of glomerular basement thickness, filtration slit length density and the classic description of the slit diaphragm as a zipper-like structure with rectangular pores [28]. This description of the slit membrane remains controversial, since it may be an artifact caused by the tannic acid fixation method [29]. In this study the slit membrane usually was located above the site of measurement on the micrographs and no details of this structure were visible. The observed relationships between level of GFR and slit width are at variance with results obtained in the streptozotozin-diabetic rat. In this model of diabetes a decrease in filtration slit width was observed in the diabetic group which presumably has higher GFR but also increased AER compared to control subjects $(37 \pm 5$ vs $32 \pm 4 \mu \mathrm{g} / \mathrm{min} p<0.05$ ) (R. Rash, personal communication).

Since, as in Figures 2 and 5 , the changes in width of slits and of foot processes seem to mirror each other it is worth mentioning that one type of change is not necessarily a consequence of the other, even elimination of all slits (to class 0 ) could not account quantitatively for the increase in foot process width. Further, assuming unchanged total tuft surface, the average foot process width depends on total length of individual foot processes, and the widening reflects a retraction of foot process as the surface of the epithelial cells changes to a less complicated configuration. Still, the two types of changes observed in the present study may have a common denominator. Both structures are labile, and may change with varying contraction of the actin apparatus which is abundant in the foot processes [30]. It is remarkable that occlusion of slits was a fairly common phenomenon observed in all of the groups and therefore was not caused by the disease.

The glomerular epithelial cells and the filtration slit membrane are coated with negatively charged glycoproteins rich in sialic acid [31] and one function of this coat material is to maintain the normal structure [32]. Podocalyxin is the major sialoprotein of the rat glomerulus and its net negative charge is derived from sulphate and sialic acid residues [33]. Much interest in recent years has concerned loss of negative charges in the filtration barrier in diabetes $[34,35]$. A reduction in the width of the filtration slit might theoretically derive from a progressive loss of negative charges which would favour the transit of a polyanion such as albumin across the glomerular barrier. Loss of charge selectivity and of immunohistochemically-identified negative sites of heparan sulphate proteoglycans in the glomerular membrane have been reported in IDDM patients with proteinuria [36, 37]. These subtle biochemical changes in the cell environment might lead to changes in cell shape and cell-to-cell distances as reported in the present study. 
Acknowledgements. The project has been supported by grants from Juvenile Diabetes Foundation International, including grant \# 190592, the Department of Health UK, Karen Elise Jensen's Foundation, Helen and Ejnar Bjørnov's Foundation, Novo Nordisk Foundation, The Danish Diabetes Association, The Danish Medical Research Council and Aarhus University Research Foundation. The technical assistance of Ms. J. Arve, $\mathrm{K}$. Gerlach and B. Saugbjerg is gratefully acknowledged.

\section{References}

1. Viberti GC, Hill RD, Jarrett RJ, Argyropoulos A, Mahmud U, Keen H (1982) Microalbuminuria as a predictor of clinical nephropathy in insulin-dependent diabetes mellitus. Lancet I:1430-1432

2. Mogensen CE, Christensen CK (1984) Predicting diabetic nephropathy in insulin-dependent patients. N Engl J Med 311: 89-93

3. Mogensen CE (1990) Prediction of clinical diabetic nephropathy in IDDM patients. Alternatives to microalbuminuria? Diabetes 39: 761-767

4. Mauer SM, Steffes MW, Ellis EN, Sutherland DER, Brown DM, Goetz FC (1984) Structural-functional relationships in diabetic nephropathy. J Clin Invest 74: 1143-1155

5. Østerby R, Gundersen HJG, Nyberg G, Aurell M (1987) Advanced diabetic glomerulopathy. Quantitative structural characterization of nonoccluded glomeruli. Diabetes 36: 612-619

6. Østerby R, Parving HH, Hommel E, Jørgensen HE, Løkkegaard H (1990) Glomerular structure and function in diabetic nephropathy. Early to advanced stages. Diabetes 39: 1057-1063

7. Walker JD, Close CF, Jones SL et al. (1992) Glomerular structure in type-1 (insulin-dependent) diabetic patients with normo- and microalbuminuria. Kidney Int 41: 741-748

8. Bangstad HJ, Østerby R, Dahl-Jørgensen K et al. (1993) Early glomerulopathy is present in young, type 1 (insulindependent) diabetic patients with microalbuminuria. Diabetologia 36: 523-529

9. Bangstad HJ, Østerby R, Dahl-Jørgensen K, Berg KJ, Hartmann A, Hanssen KF (1994) Improvement of blood glucose control in IDDM patients retards the progression of morphological changes in early diabetic nephropathy. Diabetologia 37: 483-490

10. Bohman SO, Jaremko G, Bohlin AB, Berg U (1984) Foot process fusion and glomerular filtration rate in minimal change nephrotic syndrome. Kidney Int 25: 696-700

11. Seefeldt T, Bohman SO, Gundersen HJG, Maunsbach AB, Petersen VP, Olsen S (1981) Quantitative relationship between glomerular foot process width and proteinuria in glomerulonephritis. Lab Invest 44: 541-546

12. Ellis EN, Steffes MW, Chavers B, Mauer SM (1987) Observations of glomerular epithelial cell structure in patients with type I diabetes mellitus. Kidney Int 32: 736-741

13. Østerby R, Andersen AR, Gundersen HJ, Jørgensen HE, Mogensen CE, Parving HH (1984) Quantitative studies of glomerular ultrastructure in type I diabetics with incipient nephropathy. Diabetic Nephropathy 3: 95-100

14. Farquhar MG (1975) The primary glomerular filtration barrier-basement membrane or epithelial slits? Kidney Int 8: 197-211

15. Daniels BS, Deen WM, Mayer G, Meyer T, Hostetter TH (1993) Glomerular permeability barrier in the rat. Functional assessment by in vitro methods. J Clin Invest 92: 929-936
16. Drumond MC, Deen WM (1992) Structural determinants of glomerular capillary hydraulic permeability. J Am Soc Nephrol 3: 560 (Abstract)

17. Mogensen CE (1988) Definition of diabetic renal disease in insulin-dependent diabetes mellitus based on renal function tests. In: Mogensen CE (ed) The kidney and hypertension in diabetes mellitus. Martinus Nijhoff Publishing, Boston Dordrecht Lancaster, pp 7-16

18. Maunsbach AB (1966) The influence of different fixatives and fixation methods on the ultrastructure of rat kidney proximal tubule cells. II. Effects of varying osmolality, ionic strength, buffer system and fixative concentration of glutaraldehyde solutions. J Ultrastruct Res 15: 283-309

19. Østerby R, Gundersen HJG (1978) Sampling problems in the kidney. In: Miles RE, Serra J (eds) Lecture notes in biomathematics, vol 23. Springer, Berlin Heidelberg New York, pp 185-191

20. Weibel ER (1980) Stereological methods. Practical methods for biological morphometry, vol 1. Academic Press, New York

21. Microalbuminuria Collaborative Study Group (1993) Risk factors for development of microalbuminuria in insulin dependent diabetic patients: a cohort study. BMJ 306: 12351239

22. Gundersen HJG, Seefeldt T, Østerby R (1980) Glomerular epithelial foot processes in normal man and rats. Distribution of true width and its intra- and inter-individual variation. Cell Tissue Res 205: 147-155

23. Steffes MW, Leffert JD, Basgen JM, Brown DM, Mauer SM (1980) Epithelial cell foot process width in intact and uninephrectomized diabetic and nondiabetic rats. Lab Invest 43: 225-230

24. Østerby R, Nyberg G, Hedman L, Karlberg I, Persson H, Svalander C (1991) Kidney transplantation in type 1 (insulin-dependent) diabetic patients. Early glomerulopathy. Diabetologia 34: 668-674

25. Furukawa T, Ohno S, Oguchi H, Hora K, Tokunaga S, Furuta S (1991) Morphometric study of glomerular slit diaphragms fixed by rapid-freezing and freeze-substitution. Kidney Int 40: 621-624

26. Mogensen CE, Østerby R, Gundersen HJ (1979) Early functional and morphologic vascular renal consequences of the diabetic state. Diabetologia 17: 71-76

27. Shea SM, Morrison AB (1975) A stereological study of the glomerular filtre in the rat. Morphometry of the slit diaphragm and basement membrane. J Cell Biol 67: 436-443

28. Schneeberger EE, Levey RH, McCluskey RT, Karnowsky MJ (1975) The isoporous substructure of the human glomerular slit diaphragm. Kidney Int 8: 48-52

29. Ohno S, Hora K, Furukawa T, Oguchi H (1992) Ultrastructural study of the glomerular slit diaphragm in fresh unfixed kidneys by a quick-freezing method. Virchows Arch B Cell Pathol 61: 351-358

30. Drenckhahn D, Franke RP (1988) Ultrastructural organization of contractile and cytoskeletal proteins in glomerular podocytes of chicken, rat, and man. Lab Invest 59: 673682

31. Tisher CC, Brenner BM (1989) Structure and function of the renal glomerulus. In: Tisher CC, Brenner BM (eds) Renal pathology with clinical and functional correlations. Publishing House, Philadelphia London Mexico New York, pp 92-110

32. Heptinstall RH (1983) Pathology of the kidney. Vol. II. The nephrotic syndrome, filtration of macromolecules. Little, Brown, Boston Toronto, pp 638-650

33. Dekan G, Gabel C, Farquhar MG (1991) Sulphate contributes to the negative charge of podocalyxin, the major sialo- 
glycoprotein of the glomerular filtration slits. Proc Natl Acad Sci USA 88: 5398-5402

34. Deckert T, Feldt-Rasmussen B, Borch-Johnsen K, Jensen T, Kofoed-Enevoldsen A (1989) Albuminuria reflects widespread vascular damage. The Steno hypothesis. Diabetologia 32: 219-226

35. Deckert T, Kofoed-Enevoldsen A, Vidal P, Nørgaard K, Andreasen HB, Feldt-Rasmussen B (1993) Size- and charge selectivity of glomerular filtration in type 1 (insulin-dependent) diabetic patients with and without albuminuria. Diabetologia 36: 244-251
36. Vernier RL, Steffes MW, Sisson-Ross S, Mauer SM (1992) Heparan sulphate proteoglycan in the glomerular basement membrane in type 1 diabetes mellitus. Kidney Int 41: 1070-1080

37. Shiromura H, Spiro RG (1987) Studies on macromolecular components of human glomerular basement membrane and alterations in diabetes. Decreased levels of heparan sulphate proteoglycan and laminin. Diabetes 36: 374-381 